\title{
Gas Hydrates as a Means for Biogas and Biomethane Distribution
}

\author{
Elham Ahmadi Moghaddam ${ }^{1,2 *}$, Anders Larsolle², Pernilla Tidåker ${ }^{2}$ and Åke Nordberg² \\ ${ }^{1}$ Department of Management and Engineering, Linköping University, Linköping, Sweden, ${ }^{2}$ Department Energy \\ and Technology, Faculty of Natural Resources and Agricultural Sciences, Swedish University of Agricultural Sciences (SLU), \\ Uppsala, Sweden
}

OPEN ACCESS

Edited by:

Joni Jupesta,

Research Institute of Innovative Technology for the Earth, Japan

Reviewed by:

Godwin Norense Osarumwense Asemota,

University of Rwanda, Rwanda Ehsan Rasoulinezhad, University of Tehran, Iran

*Correspondence: Elham Ahmadi Moghaddam elham.moghaddam@liu.se

Specialty section:

This article was submitted to Sustainable Energy Systems and Policies,

a section of the journal

Frontiers in Energy Research

Received: 02 June 2020 Accepted: 12 March 2021 Published: 07 April 2021

Citation:

Moghaddam EA, Larsolle A, Tidåker P and Nordberg $\AA$ (2021) Gas

Hydrates as a Means for Biogas and Biomethane Distribution.

Front. Energy Res. 9:568879. doi: 10.3389/fenrg.2021.568879
Biomethane is receiving great attention as a renewable energy gas with lower environmental impacts and diversified sources of production. However, availability of gas infrastructure is an important factor in biomethane development and use. Biomethane can be distributed by the natural gas or local biogas grid. Biomethane can also be road-transported as compressed biomethane (CBG) or liquefied biomethane (LBG). Biomethane could be distributed via gas hydration technology, where methane molecules are physically trapped within the crystalline structures of frozen host water molecules as gas hydrate compounds. Using life cycle assessment methodology, this study compared the energy performance and climate impact of two gas hydrate scenarios, biogas hydrate and biomethane hydrate, with that of a base case distributing biomethane as CBG. The technical system, from biogas upgrading, hydration, compression and road transport to filling station of biomethane as CBG, was included in the analysis. Results of this study show that distribution of biomethane as gas hydrates had a lower energy performance and higher climate impact than compressed biomethane distribution. The low energy performance was due to high electricity demand in hydrate formation and dissociation processes. The gas hydrate scenarios also had higher climate impacts as a result of high methane losses from hydrate formation and dissociationdissociation and emissions related to energy source use. Biogas upgrading to biomethane also significantly contributed to methane losses and climate impact of the scenarios studied.

Keywords: biogas hydrate, biomethane hydrate, compressed biomethane, life cycle assessment, primary energy inputs, climate impact

\section{INTRODUCTION}

Biomethane is a versatile biomass-derived renewable energy carrier with the ability to produce energy services and high-value products. The digestion of organic matter results in biogas containing approximately $45-65 \%$ by volume $(\mathrm{v} / \mathrm{v})$ of methane $\left(\mathrm{CH}_{4}\right)$ and $25-30 \% \mathrm{v} / \mathrm{v}$ of carbon dioxide $\left(\mathrm{CO}_{2}\right)$ with the remaining consisting of hydrogen sulfide $\left(\mathrm{H}_{2} \mathrm{~S}\right)$, moisture and siloxanes. The energy content of biogas can be increased through drying, cleaning and upgrading, resulting in biomethane with $>97 \% \mathrm{CH}_{4}$ (Wellinger et al., 2013). In 2018, total biogas production in Sweden was around 2.1 TWh, of which 1.3 TWh was upgraded to biomethane. Approximately $42 \%$ of this biomethane was injected to gas grids in south-west Sweden and Stockholm. The remaining biomethane was stored and road-transported as compressed biomethane (CBG; 200 bar) in an "offgrid" solution due to lack of gas grid infrastructure. However, $44 \mathrm{GWh}$ were converted to liquefied biomethane (LBG) at one plant (Swedish Energy Agency, 2018). 
The greatest drivers of biogas use are a sustainable and renewable alternative that can contribute to a fossil-free transport sector and reduce organizations' environmental and climate impact. Energy and carbon dioxide tax exemptions, local alternative and circular economy, high consumer demands for sustainability, and possible competitive advantage are among the other driver of biogas use in the transport sector in Sweden (Geerolf, 2018).

The storage and transport system for CBG consists of steel or composite cylinders filled to a pressure of approximately 200 bar and road transport to central gas filling stations or industrial consumers (Hjort and Tamm, 2012; Budzianowski and Brodacka, 2017). Gas upgrading and compression are the most energy demanding stages, representing approximately $13 \%$ of the energy content of the biogas (Moghaddam et al., 2015). However, an issue related to CBG is the overall weight of the truck, including the load, in comparison with the amount of gas transported. Distribution as compressed biomethane (CBG) has a low energy density compared with liquid fuels and is a suitable option for dispensing and distribution in the vicinity of a local biogas plant. Another alternative for biomethane distribution is to liquefy biomethane at low temperature of $-161^{\circ} \mathrm{C}$ for road transportation as a liquid fuel. However, LBG is an energy intensive technology restricted to large-scale biomethane production units ( $>30 \mathrm{GWh} /$ year) and, due to the increase in temperature of the LBG tank during storage and transportation, LBG will evaporate, creating boil-off gas (Hjort and Tamm, 2012).

Selection of an appropriate transport and storage system for biomethane has a significant impact on the overall efficiency of biomethane system performance (Budzianowski and Brodacka, 2017). Apart from compression (i.e., CBG) and liquefaction (i.e., LBG), biomethane has the possibility to be stored and transported through physical conversion of $\mathrm{CH}_{4}$ molecules. In this method, $\mathrm{CH}_{4}$ is converted to clathrate hydrates, which are compounds in which $\mathrm{CH}_{4}$ molecules are physically trapped within the crystalline structures of frozen host water molecules. The required pressure for hydrate formation is around 30-100 bar and the temperature usually needs to be between -15 and $-32^{\circ} \mathrm{C}$ (Budzianowski and Brodacka, 2017).

Gas hydrates is characterized by high storage capacity. Theoretically, a given volume of gas hydrates contains more than 150-fold the same volume of gas at standard temperature and atmospheric pressure, which shows that gas hydrates are promising for gas storage (Mori, 2003; Siažik et al., 2017). Compared to other biomethane storage and distribution methods (i.e., gas grid, gas liquification, gas compression) hydrate technology has the advantage of high safety and flexibility (Wu et al., 2019). In nature, gas hydrates are stable sources of gas existing under natural conditions of elevated pressure and low temperature found in marine sediments and permafrost regions, which abound in conventional deposits of natural gas (Sloan and Koh, 2007). Gas hydrates may be a suitable means of biomethane storage and transport in Sweden, due to low environmental temperatures and lack of grid infrastructure. Introducing methane hydrate in the logistics chain between the producer and consumer of biomethane would result in three main stages; formation of hydrates, storage of hydrates and dissociation of hydrates.

Formation of hydrates: Gas hydrates are produced by bringing liquid water into contact with gas at the appropriate temperature and pressure. The formation of gas hydrates can take place in a continuous stirred tank reactor, where the gas is injected into liquid water. The necessary cooling is provided by an ice/water slurry, which is injected into the reactor. During the formation process, gas mixes of $\mathrm{CH}_{4}$ and $\mathrm{CO}_{2}$ molecules are captured in polyhedral structures consisting of hydrogen bonded water molecules. The molecular structure is theoretically $8 \mathrm{G}_{4} 6 \mathrm{H}_{2} \mathrm{O}$, and the gas to water mole ratio is 0.1739 , which represents a hydration number of 1:5.75 (Kang et al., 2009). According to Uchida et al. (2005), guest molecules of $\mathrm{CH}_{4}$ and $\mathrm{CO}_{2}$ are incorporated into hydrate structures in proportion to their concentration in the feed gas.

Storage and transport of gas hydrates: After formation, hydrates are stored in containers at near adiabatic conditions. Gas hydrates remain stable during storage and transport at atmospheric pressure and freezing temperatures ( -5 to $-15^{\circ} \mathrm{C}$ ), representing similar physical conditions to those of simple hydrates (Gudmundsson et al., 1999, 1994). During storage of mixed gas hydrates, the cage structures enclathrating $\mathrm{CH}_{4}$ molecules are more stable than those enclathrating $\mathrm{CO}_{2}$ molecules. This allows loss of $\mathrm{CO}_{2}$ and increased concentration of $\mathrm{CH}_{4}$ in the structured ice. However, the decomposition rate of frozen gas at atmospheric temperature is negligible. Some studies report no gas hydrate decomposition within years of storage (Ershov and Yakushev, 1992; Sun et al., 2019). Gashydrate compounds are distributed to a transportation unit with a suitable storage container to transport/store the hydrate at adiabatic conditions at atmospheric pressure or at a slight gauge pressure at a temperature below $0^{\circ} \mathrm{C}$., preferably at $-10^{\circ} \mathrm{C}$. to $-15^{\circ} \mathrm{C}$ (Gudmundsson, 1996).

Dissociation of hydrates: Dissociation of hydrates can be performed in three different ways; by increasing the temperature, by decreasing the pressure or by adding an inhibitor to the hydrate. During thermal dissociation, $\mathrm{CO}_{2}$ is more easily released than $\mathrm{CH}_{4}$. However, hydrates with a higher $\mathrm{CO}_{2}$ concentration tend to decompose more than those with less $\mathrm{CO}_{2}$ (Pang et al., 2009; Kwon et al., 2011; Wang et al., 2017).

When proposing novel systems for distribution and transport of biomethane, there is a need to analyze the energetic and environmental performance in a systems perspective, including a comparison with conventional techniques. The approach adopted in this study was to evaluate the energy performance and climate impact associated with implementation of gas hydrates from biogas and biomethane produced in a smallscale anaerobic digestion unit using life cycle assessment (LCA). The LCA methodology is applicable for compiling and evaluating potential environmental impacts of a product system throughout its life cycle (ISO, 2006a,b) and has been extensively used for comparisons of different bioenergy systems (e.g., Cherubini and Strømman, 2011). Through a life cycle perspective, environmental hotspots can be highlighted, for identification of potential improvements. This is important when evaluating future-oriented 
scenarios, including technology not yet implemented in a specific setting.

\section{Methods}

Life cycle assessment methodology was used to assess the energy performance and climate impact of three different biogas distribution system scenarios related to a small-scale biogas production unit with $\mathrm{CBG}$ as the final product. The scenarios were a conventional system based on road transport of $\mathrm{CBG}$ and two future-oriented scenarios based on gas hydration (i.e., biogas hydrates and biomethane hydrates). Climate impact and energy inputs were calculated throughout the life cycle, from raw biogas upgrading to gas compression, hydrate formation and dissociation in the gas hydrate scenarios, storage and road transport to filling station. Distribution of biomethane as CBG was assumed as the base scenario, to which gas hydrate distribution technologies were compared. The LCA method used is described in ISO standards 14040 and 14044 (ISO, 2006a,b) and is similar to the methodology described in the sustainability criteria for biofuels in the European Union Directive (2009). Further, an attributional modeling approach was used, in which the inputs and outputs were attributed to the functional unit of a product system by linking and/or partitioning the unit processes of the system (Curran,2015). This can be compared with consequential LCA modeling, which examines the environmental consequences of marginal changes in a life cycle, often with a market-oriented approach (Zamagni et al., 2012).

Energy use was studied as primary energy (PE) input. Factors used for conversion of data on electricity and diesel to PE has been assessed from Ecoinvent (2017) and are presented in Table 1. The PE factor is defined as the ratio between PE input and delivered useful energy. Included in PE are extraction of fuel, transportation and conversion, transmission and distribution losses. The electricity required for the processes was assumed to be Swedish electricity mix, mainly consisting of electricity produced from hydropower (43\%) and nuclear power (41\%) (Byman, 2016). Energy performance was assessed by both the total PE inputs and the ratio between delivered biomethane and primary energy inputs. It was assumed that the surplus low-grade heat generated left the system and it was not accounted for or valorized in calculations.

The climate impact, expressed as global warming potential (GWP), considered the upstream and downstream emissions

TABLE 1 | Primary energy (PE) and climate impact factors for different energy carriers. $^{1}$

\begin{tabular}{lccc}
\hline Energy carrier & Specifications & $\begin{array}{c}\text { PE factor } \\
\text { (MJ/MJ) }\end{array}$ & $\begin{array}{c}\text { Climate impact } \\
\text { (g CO }\end{array}$ \\
\hline Electricity & Swedish electricity mix & 1.6 & 16 \\
& Hydropower & 1.0 & 1.1 \\
& Natural gas & 2.0 & 100 \\
Fuel & Diesel, low-sulphur & 1.3 & 77 \\
Natural gas & Fossil & 1.1 & 7.4 \\
\hline
\end{tabular}

${ }^{1}$ Ecoinvent ver.3-4 (2017). of greenhouse gases (GHGs), i.e., $\mathrm{CO}_{2}, \mathrm{CH}_{4}$ and nitrous oxide $\left(\mathrm{N}_{2} \mathrm{O}\right)$, during the life cycle of biomethane distribution systems in the three different scenarios. Thus, emissions occurring inside the system boundaries, such as emissions related to input resources (i.e., input electricity and diesel), transportation and different technical units (i.e., gas compression, biogas upgrading, gas hydration and dissociation) were included in the calculations. The emissions were calculated as $\mathrm{CO}_{2}$-equivalents $\left(\mathrm{CO}_{2}\right.$-eq. $)$, using characterization factors for a 100-year perspective based on IPCC (2006). The characterization factor used when calculating GWP100 was 28 and 30 for biogenic and fossil $\mathrm{CH}_{4}$, respectively, and 265 for $\mathrm{N}_{2} \mathrm{O}$ (Stocker et al., 2013). Biogenic $\mathrm{CO}_{2}$ was not included in the GHG accounting.

\section{Functional Unit and System Boundaries}

The functional unit (FU) was defined as $1 \mathrm{Nm}^{3}$, biogas $\left(60 \% \mathrm{CH}_{4}\right.$, $40 \% \mathrm{CO}_{2}$ at 1 bar and $0^{\circ} \mathrm{C}$ ) leaving the anaerobic digester and entering the system boundary for each scenario. The anaerobic digestion process (handling and use of substrate, plant operation and use of digestate) was assumed to be identical for all three scenarios assessed and was therefore not included in the analysis. The system boundary of the study encompassed the following processes:

- Biogas cleaning and upgrading,

- Compression to CBG,

- Physical conversion to biogas hydrate and biomethane hydrate,

- Storage and distribution to a gas filling station.

Embodied impacts of capital equipment and infrastructure production of capital goods, such as machinery and buildings, were not included in the calculations, due to their minor influence on the results (Grant and Bengtsson, 2017).

\section{Sensitivity Analysis}

Assessment of future-oriented scenarios, such as the hydrate scenarios, is associated with high un-certainty since little data are available from implementation in real settings. Since assumptions made in a scenario study might be critical for the outcome and the results, a sensitivity analysis was performed. In this, the influence of transport distance, choice of electricity mix, $\mathrm{CH}_{4}$ emission levels from the upgrading unit, hydration efficiency and $\mathrm{CH}_{4}$ emissions during gas handling in hydration and dissociation processes on the total PE input and GHG emissions was evaluated.

\section{System Description System Description Overview and General Assumptions}

The assessment was based on small-scale biogas production of $40 \mathrm{Nm}^{3} / \mathrm{h}$ of raw biogas ( 1 bar and $0^{\circ} \mathrm{C}$ ) with a composition of $60 \% \mathrm{CH}_{4}$, and $40 \% \mathrm{CO}_{2}$. The annual gross energy equivalent of the biogas produced was $2096 \mathrm{MWh}$, based on $9.97 \mathrm{kWh} / \mathrm{Nm}^{3}$ $\mathrm{CH}_{4}$. The base scenario reflected conventional management of biogas, i.e., raw biogas was assumed to be cleaned, upgraded and compressed in cylindrical tanks to CBG at the biogas plant 

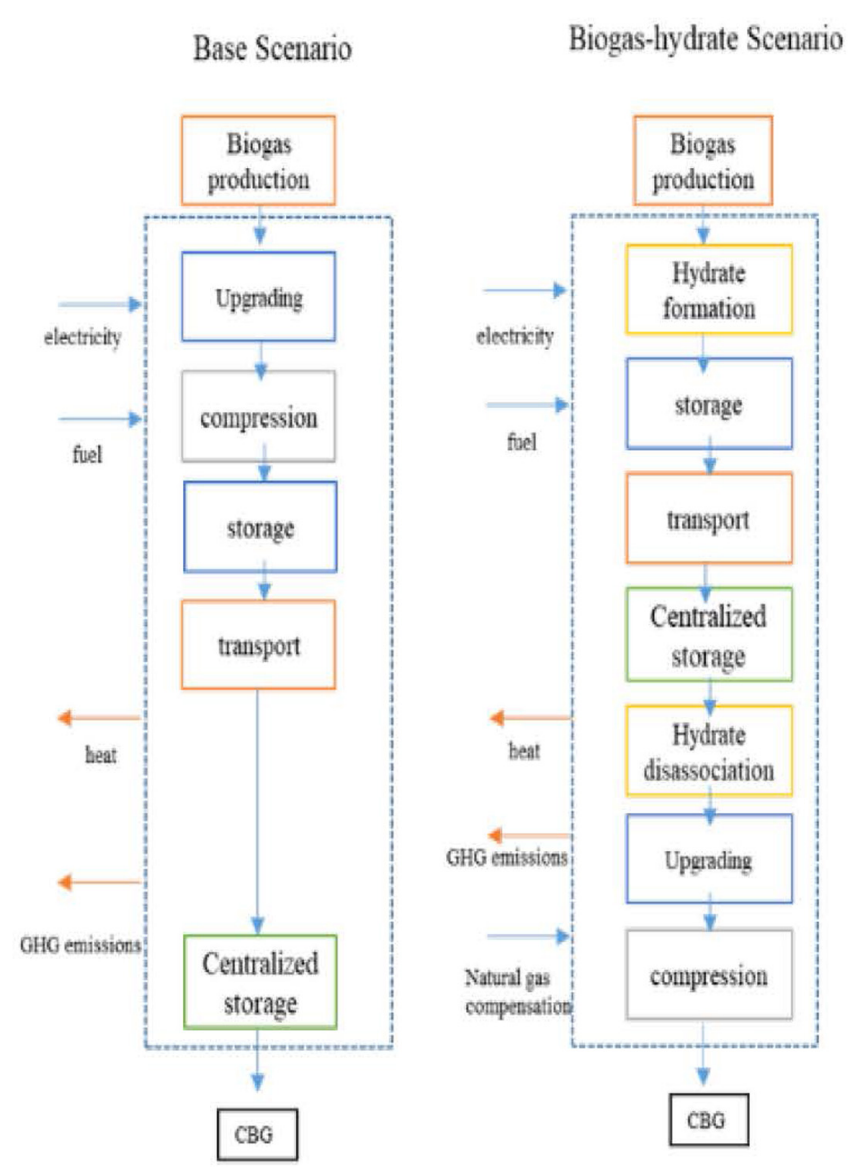

\section{Biomethane-hydrate Scenario}

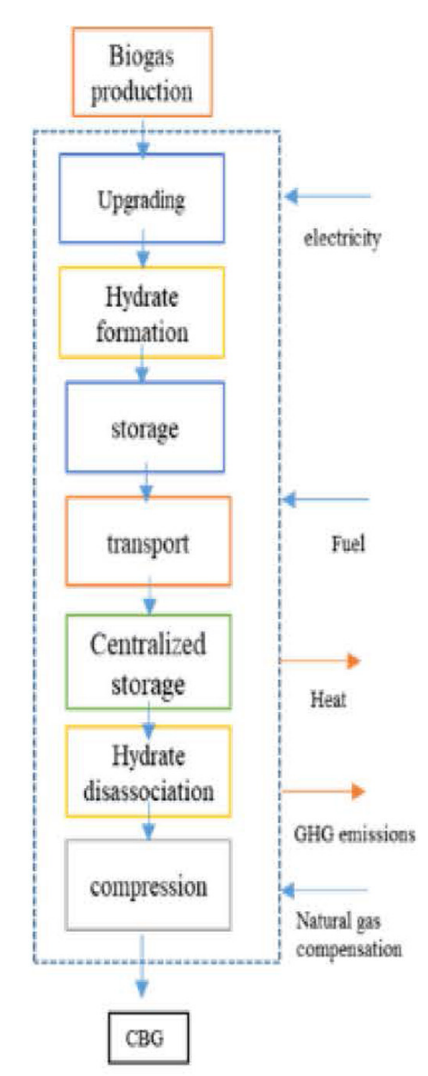

FIGURE 1 | Flow chart and system boundaries of the three scenarios studied.

and transported to a centralized facility for storage and further use (Figure 1). In the biogas hydrate scenario, raw biogas was assumed to be converted to hydrate at the biogas plant and transported in containers to a centralized facility for storage and further gas handling, thereafter dissociation of hydrate, upgrading and compression to CBG. In the biomethane hydrate scenario, raw biogas was assumed to be upgraded to biomethane and converted to hydrate at the biogas plant for transportation in containers to a centralized facility for storage and thereafter dissociation of hydrate and compression to CBG. The output from all three scenarios was CBG at 200 bar. In all scenarios, storage time at the biogas plant was determined by the storage container capacity of one transport of containers. The assumed storage time at the final destination was set to 14 days. The transport distance from the biogas plant to the central facility was set to $100 \mathrm{~km}$. Model implementation and scenario calculations were performed using a previously developed calculation and modeling platform (Norberg et al., 2013). The surplus low value heat leaving the system was not valorized or accounted for. In all scenarios, the upgrading unit had a $\mathrm{CH}_{4}$ loss of $1 \%$ of the biomethane produced (Lantz et al., 2009). Handling operations during gas hydration and dissociation were assumed to result in a $\mathrm{CH}_{4}$ loss of $2 \%$ of the biomethane produced. The lower biomethane output from the hydrate scenarios due to gas losses was compensated for by natural gas, in order to reach an equal output to that in the base scenario.

\section{Base Scenario}

The small-scale upgrading was based on a decentralized water scrubbing technique with a lower pressure requirement and lower energy demand than conventional water absorption technologies (Bauer et al., 2013). The required electricity was $0.20 \mathrm{kWh} / \mathrm{Nm}^{3}$ rawbiogas and compression of bio-methane to 200 bar based on four compression stages required 0.23 $\mathrm{kWh} / \mathrm{Nm}^{3}$ rawbiogas according to Bauer et al. (2013). The compressed biomethane was assumed to be transported in pressurized steel vessels on a hook-lift truck with a capacity of $4,000 \mathrm{Nm}^{3}$ biomethane per truck (Norberg et al., 2013) and diesel consumption of $0.48 \mathrm{~L} / \mathrm{km}$ (Benjaminsson and Nilsson, 2009). The storage time for $\mathrm{CBG}$ at the biogas plant was 6.9 days, based on the storage container capacity for one transport.

\section{Biogas Hydrate Scenario}

The hydrate formation process was divided into compression work, gas cooling, water cooling, hydrate formation, and pumping and mixing (Figure 2). The equilibrium pressure and temperature profile were obtained from Arca et al. (2011). The biogas was assumed to be compressed in two stages 


\section{Water $\mathrm{T}=14.8^{\circ} \mathrm{C}$}

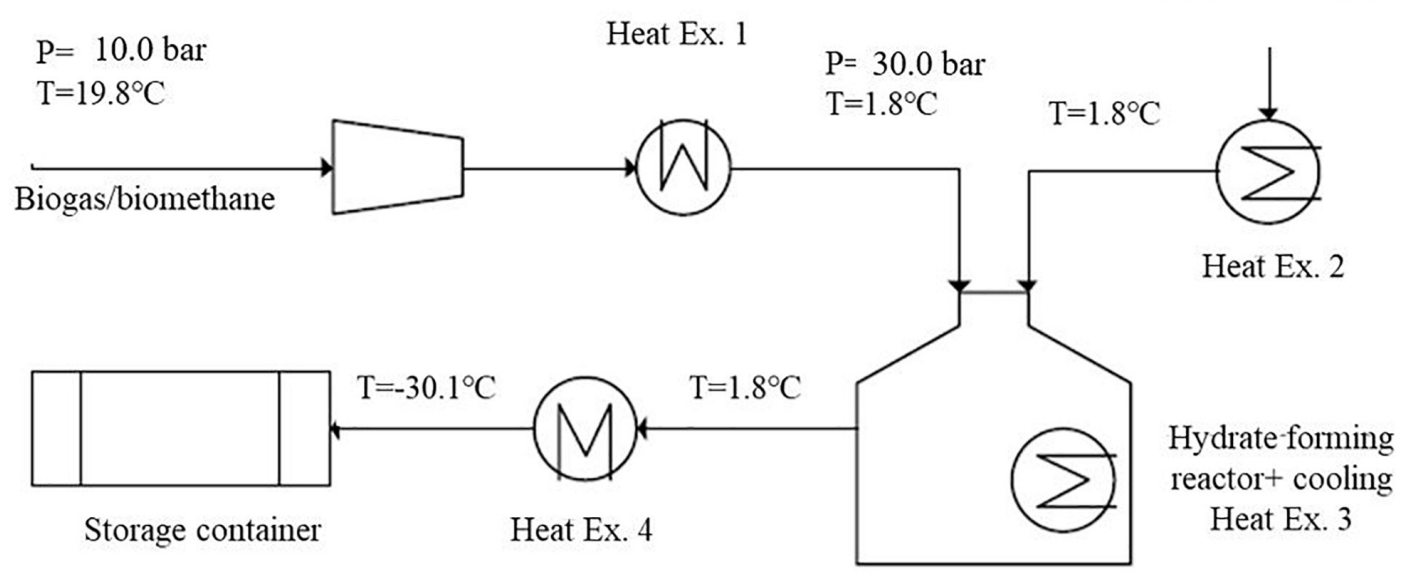

FIGURE 2 | Flow scheme of the hydrate formation processes invoking four heat exchangers (Heat Ex. 1-4).

with equivalent compression ratio and compressor efficiency of 0.8 (isoentropic work). The gas cooling power demand was calculated from 20 to $2^{\circ} \mathrm{C}$ for a heat exchanger (Heat Ex. 1) with a thermal exchange efficiency of 0.75 . The power for cooling the water entering together with the gas to the hydrate formation reactor was correspondingly calculated from an inlet temperature of 15 to $2^{\circ} \mathrm{C}$ and a heat exchanger efficiency of 0.75 (Heat Ex. 2). The cooling power required for the hydrate formation was calculated based on the hydrate dissociation enthalpy for $\mathrm{CH}_{4}$ and $\mathrm{CO}_{2}$ (54.5 and $61 \mathrm{~kJ} / \mathrm{mol}$, respectively) according to Kwon et al. (2011), and with a cooling efficiency of 0.75 (Heat Ex. 3). A gas-to-water stoichiometric ratio of 1:5.75 for hydrate formation was assumed, with a water conversion efficiency of 0.8 (Arca et al., 2011), thus resulting in a ratio of 1:7.1875 for the calculations. The power for cooling the hydrate to a storage temperature of $-30^{\circ} \mathrm{C}$ was calculated for a heat exchanger (Heat Ex. 4) with a thermal efficiency of 0.75. A compression chiller with a coefficient of performance (COP) of 3.0 was assumed for the gas and water cooling. The power demand for pumping and mixing inside the hydrate formation reactor was approximated to $5 \%$ of the entire process demand. After formation, the hydrate was assumed to be transferred to, and stored in, gastight freezing containers consisting of three jacketed vessels with a total inner volume of $11.1 \mathrm{~m}^{3}$. The density of hydrate was set to $0.9 \mathrm{t} / \mathrm{m}^{3}$ (Wang et al., 2017), leading to a weight capacity of 10 tons of hydrate per container. Ethanol was selected to be the refrigerant surrounding the vessels and each jacketed vessel was assumed to be isolated with $10 \mathrm{~cm}$ of styrofoam. The freezing containers were assumed to be transported by a truck equipped with a hook lift and with a total capacity of three containers, resulting in a storage time of 4 days at the biogas plant.

The hydrate was assumed to be cooled to $-30^{\circ} \mathrm{C}$ at the plant and no further cooling power in transport and storage at the centralized facility was needed. The maximum temperature of the hydrate before dissociation was set to $-10^{\circ} \mathrm{C}$. Heat required for dissociation of the hydrates was the heat for melting the hydrate from -10 to $0^{\circ} \mathrm{C}$ and the dissociation enthalpy. This heat was supplied by a compression heat pump with the COP set to 3 , including recovery of heat from subsequent compression of biomethane to 200 bar (Figure 3). Upgrading at the central facility was by conventional water scrubber with a capacity of $320 \mathrm{Nm}^{3}$ rawbiogas/h. The electricity required for upgrading was $0.30 \mathrm{kWh} / \mathrm{Nm}^{3}$ rawbiogas and subsequent compression of biomethane to 200 bar required $0.16 \mathrm{kWh} / \mathrm{Nm}^{3}$ rawbiogas according to Bauer et al. (2013).

\section{Biomethane Hydrate Scenario}

Biogas was upgraded to biomethane in a decentralized upgrading unit similar to that in the base scenario. The equilibrium pressure and temperature profile for methane hydrate were taken from Arca et al. (2011). The working pressure was set to 40 bar and the temperature to $2^{\circ} \mathrm{C}$. Electricity demand for hydrate formation, including cooling of the hydrate to $-30^{\circ} \mathrm{C}$, was calculated with the same gas and water temperatures and efficiencies as for the biogas hydrate scenario. Calculation of weighted averages of specific heat capacity and dissociation enthalpy was based on a composition of $97 \% \mathrm{CH}_{4}$ and $3 \% \mathrm{CO}_{2}$. Storage and transport of biomethane hydrate were as assumed in the biogas hydrate scenario. The storage time at the biogas plant was 8 days, based on the storage container capacity for one transport. The heat requirement for hydrate dissociation at the centralized facility was based on melting the hydrate from $-10^{\circ} \mathrm{C}$ and the dissociation enthalpy. Recovery of heat from subsequent compression of biomethane to 200 bar was performed by a similar heat pump as used in the biogas hydrate scenario.

\section{RESULTS}

\section{Energy Input}

The PE input per FU for different units in each scenario is presented in Table 2. Total PE input in the base, biogas hydrate and biomethane hydrate scenario was 3.5, 11.5 and 8.2 $\mathrm{MJ} / \mathrm{Nm}^{3}{ }_{\text {rawbiogas, }}$ respectively. The high energy inputs in 


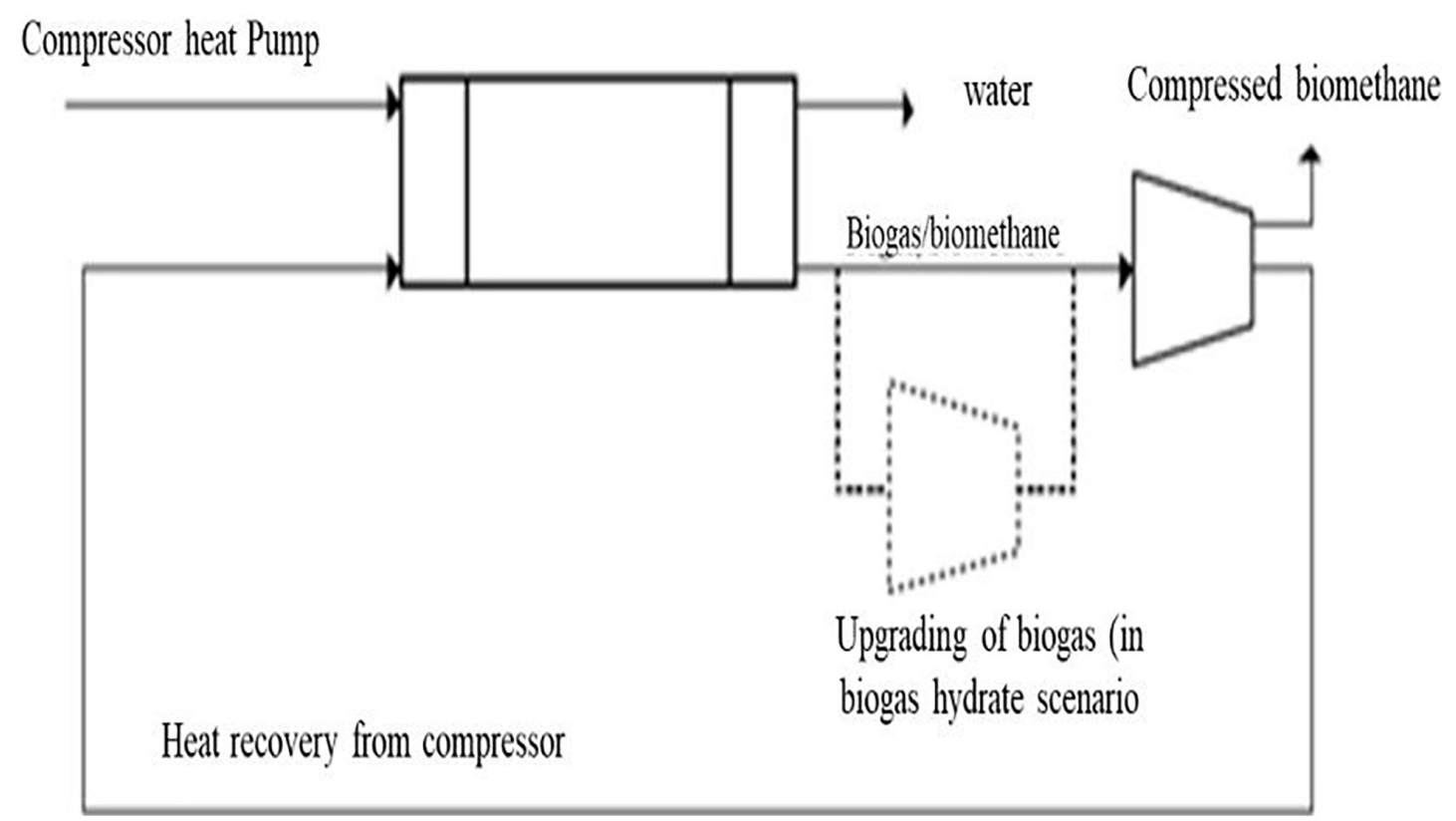

FIGURE 3 | Flow scheme of the dissociation process involving a compressor heat pump and recovery of heat from compression of biornethane.

the gas hydrate scenarios derived from high levels of electricity demand in the hydrate formation and dissociation units. The PE input to hydrate formation and dissociation in the biogas hydrate scenario was $6.4 \mathrm{MJ} / \mathrm{Nm}^{3}$ rawbiogas $(55.6 \%$ of the total $\mathrm{PE}$ input), while the corresponding PE input in the biomethane hydrate scenario was $4.1 \mathrm{MJ} / \mathrm{Nm}^{3}$ raw biogas $(50.0 \%$ of the total $\mathrm{PE}$ input). In the biogas hydrate scenario, the centralized upgrading of biogas had a higher PE input $\left(2.5 \mathrm{MJ} / \mathrm{Nm}^{3}\right.$ rawbiogas $)$ than the decentralized upgrading unit used in the biomethane hydrate and base scenarios $\left(1.7 \mathrm{MJ} / \mathrm{Nm}^{3}\right.$ rawbiogas $)$. The smallscale decentralized upgrading unit had a lower electricity demand for increasing the pressure in the water scrubber, compared with the large-scale centralized water scrubber. The compression work for producing $\mathrm{CBG}$ in the biogas hydrate scenario was slightly lower than in the other scenarios, since the compression started at a higher pressure due to the pressure build-up in the upgrading

TABLE 2 | Primary energy (PE) inputs (MJ/Nm ${ }^{3}$ rawbiogas) for the three scenarios studied.

\begin{tabular}{lccc}
\hline & Base & Biogas hydrate & Biomethane hydrate \\
\hline $\begin{array}{l}\text { Decentralised } \\
\text { upgrading/centralised }\end{array}$ & 1.7 & 2.5 & 1.7 \\
$\begin{array}{l}\text { upgrading } \\
\begin{array}{l}\text { Decentralised } \\
\text { compression/centralised }\end{array}\end{array}$ & 1.1 & 0.8 & \\
compression & & & 1.2 \\
$\begin{array}{l}\text { Hydrate formation } \\
\text { Hydrate disassociation }\end{array}$ & & 5.5 & \\
Transport & 0.7 & 3.0 & 3.3 \\
Natural gas compensation & - & 1.0 & 1.9 \\
Total & 3.5 & 0.8 & 0.4 \\
& 13.6 & 0.8 \\
& & & 9.3
\end{tabular}

process. The main PE input in the base scenario was upgrading of biogas and compression to $200 \mathrm{bar}$, corresponding to $80 \%$ of the total PE input.

Diesel consumption for biomethane hydrate was $0.4 \mathrm{MJ} / \mathrm{Nm}^{3}{ }_{\text {rawbiogas, }}$, while it was higher for the base and biogas scenarios, corresponding to 0.7 and $1 \mathrm{MJ} / \mathrm{Nm}^{3}$ rawbiogas, respectively. The higher fuel consumption in the base and biogas hydrate scenarios was due to higher total mass transported as a result of heavy steel tanks used in the base scenario and higher density of biogas hydrates in comparison to biomethane hydrates.

The difference in biomethane $\left(\mathrm{CH}_{4}\right)$ output from the base and the hydrate scenarios was considered by compensation of natural gas in the two hydrate scenarios. The energy required for natural gas compensation in the hydrate scenarios was $0.8 \mathrm{MJ} / \mathrm{Nm}^{3}$ rawbiogas, corresponding to $2 \%$ total loss of biomethane during the gas hydrate formation and dissociation processes.

\section{Electricity Requirement for Formation and Dissociation of Hydrate}

The higher PE energy inputs to the hydrate scenarios were mainly due to the electricity demand for the hydrate formation and dissociation processes. The electricity demand $\left(\mathrm{MJ}_{\mathrm{el}} / \mathrm{Nm}^{3}\right.$ rawbiogas $)$ for formation of hydrate, cooling for storage and dissociation of hydrates is presented in Table 3. Cooling for hydrate formation and heating for dissociation were the most energy-demanding operations, making up approximately $30 \%$ and $45 \%$ of the total electricity demand, respectively, in both hydrate scenarios (Table 3). No electricity was required during storage in either of the scenarios. 


\section{Energy Performance}

The PE inputs, energy outputs and energy ratio (Outputs/Inputs) of the three scenarios are presented in Table 4. The output of all scenarios studied consisted of biomethane $\left(97 \% \mathrm{CH}_{4}\right)$, which in the hydrate scenarios was slightly lower due to losses in gas handling during hydrate formation and dissociation. The base scenario had the highest energy ratio, due to the relatively low $\mathrm{PE}$ input, whereas the biomethane hydrate scenario and biogas hydrate scenario had much lower energy ratio as a result of the high PE input.

\section{Climate Impact: Global Warming Potential (GWP)}

The contribution to climate impact of the biogas and biomethane hydrate scenarios was approximately 4 -fold and 3-fold higher, respectively, than in the base scenario (Table 5). The upgrading unit was the highest contributor in the base and biogas hydrate scenarios. Total global warming potential in the base, biogas hydrate and biomethane hydrate scenarios was 141, 567 and $416 \mathrm{~g} \mathrm{CO}_{2}$-eq $/ \mathrm{Nm}^{3}$ rawbiogas, respectively. Loss of $\mathrm{CH}_{4}$ from the upgrading unit corresponded to $120 \mathrm{~g} \mathrm{CO}_{2}$-eq. $/ \mathrm{Nm}^{3}$ rawbiogas for all scenarios. The difference in total climate impact from the upgrading unit in the three scenarios was related to the energy (i.e., electricity) demand. The centralized upgrading unit in the biogas hydrate scenario had a higher electricity demand than the decentralized upgrading unit in the biomethane hydrate and base scenarios. The hydrate formation and dissociation units

TABLE 3 | Electricity demand for the formation, storage and dissociation of hydrates.

\begin{tabular}{|c|c|c|}
\hline & $\begin{array}{c}\text { Biogas hydrate } \\
\left(60 \% \mathrm{CH}_{4}, 40 \%\right. \\
\left.\mathrm{CO}_{2}\right)\end{array}$ & $\begin{array}{c}\text { Biomethane } \\
\text { hydrate } \\
\left(97 \% \mathrm{CH}_{4}, 3 \%\right. \\
\left.\mathrm{CO}_{2}\right)\end{array}$ \\
\hline & \multicolumn{2}{|c|}{$\mathbf{M J}_{e l} / \mathrm{Nm}^{3}{ }_{\text {rawbiogas }}$} \\
\hline Compression of gas & 0.5 & 0.4 \\
\hline Cooling of gas, water and formation of hydrate & 1.2 & 0.8 \\
\hline Pumping and mixing & 0.2 & 0.2 \\
\hline Cooling of hydrate to storage temperature & 0.2 & 0.1 \\
\hline Heating for dissociation & 1.9 & 1.2 \\
\hline Total electricity demand & 4.1 & 2.7 \\
\hline
\end{tabular}

TABLE 4 | Primary energy (PE) inputs, outputs and losses, and energy ratio (O/I) for the three scenarios studied.

\begin{tabular}{lcccc}
\hline & Input & Output & Losses & Energy ratio (O/I) \\
\cline { 2 - 4 } & \multicolumn{3}{c}{${\text { (MJ/Nm }{ }^{3} \text { rawbiogas }}^{*}$ ) } & \\
\cline { 2 - 4 } & Total & Biomethane & Methane & \\
\hline Base (CBG) & 3.5 & 35.6 & 0.4 & 10.0 \\
Biogas hydrate & 11.5 & 35.3 & 0.7 & 3.0 \\
Biomethane hydrate & 9.3 & 35.3 & 0.7 & 3.7 \\
\hline
\end{tabular}

${ }^{*}$ Based on lower heating value, LHV.
TABLE 5 | Global warming potential ( $\mathrm{g} \mathrm{CO}_{2}$-eq. $/ \mathrm{Nm}^{3}$ rawbiogas) in the three scenarios studied.

\begin{tabular}{lccc}
\hline & Base (CBG) & $\begin{array}{c}\text { Biogas } \\
\text { hydrate }\end{array}$ & $\begin{array}{c}\text { Biomethane } \\
\text { hydrate }\end{array}$ \\
\hline $\begin{array}{l}\text { Upgrading/centralised } \\
\text { upgrading }\end{array}$ & 131 & 258 & 136 \\
$\begin{array}{l}\text { Compression/centralised } \\
\text { compression }\end{array}$ & 3 & 7 & 7 \\
Hydrate formation & & 133 & 119 \\
Hydrate disassociation & 9 & 150 & 143 \\
Transport & 13 & 6 & 5 \\
Natural gas compensation & 143 & 567 & 6 \\
Total & & 13 & 416 \\
\hline
\end{tabular}

produced high levels of GHG emissions, due to $\mathrm{CH}_{4}$ losses and high levels of energy input in comparison with the base scenario. Methane losses during gas handling in the hydrate formation process were 79 and $84 \mathrm{~g} \mathrm{CO}_{2}$-eq. $/ \mathrm{Nm}^{3}$ rawbiogas in the biogas and biomethane hydrate scenario, respectively. The GHG emissions related to electricity input in hydrate formation corresponded to 54 and $35 \mathrm{~g} \mathrm{CO}_{2}$-eq. $/ \mathrm{Nm}^{3}$ rawbiogas in the biogas and biomethane hydrate scenarios, respectively.

Methane losses during gas handling in the hydrate dissociation process were 102 and $113 \mathrm{~g} \mathrm{CO}$-eq. $/ \mathrm{Nm}^{3}$ rawbiogas in the biogas and biomethane hydrate scenarios, respectively. The GHG emissions related to energy input in hydrate dissociation corresponded to 48 and $30 \mathrm{~g} \mathrm{CO}_{2}$ eq. $/ \mathrm{Nm}^{3}$ rawbiogas in the biogas and biomethane hydrate scenario, respectively. The climate impact from compression of biomethane to CBG only related to electricity use. The climate impact associated with transport of biogas hydrate was higher than in the biomethane hydrate and base scenarios (Table 5).

The climate impact of natural gas compensation in the hydrate scenarios was $6 \mathrm{~g} \mathrm{CO}_{2}$-eq. $/ \mathrm{Nm}^{3}$ rawbiogas, corresponding to $2 \%$ total loss of biomethane in the gas hydrate formation and dissociation units.

\section{Sensitivity Analysis}

Sensitivity analysis was performed to examine the impact of data uncertainties on the energy performance and climate impact. The parameters tested were transport distance, choice of electricity mix, $\mathrm{CH}_{4}$ losses from the upgrading unit, $\mathrm{CH}_{4}$ losses during gas handling in the hydrate scenarios and hydration efficiency (Tables 6, 7).

The sensitivity to transport distance was analyzed in order to determine the influence of larger transport distances for the three scenarios. Increased transport distance to $1,000 \mathrm{~km}$ was compared with $100 \mathrm{~km}$ in the base scenario. The results showed a large relative increase in PE input and climate impact per FU for the base scenario compared with the hydrate scenarios. Increasing the transport distance to $1,000 \mathrm{~km}$ increased the $\mathrm{PE}$ inputs to $11.0,17.0$ and $11.7 \mathrm{MJ} / \mathrm{Nm}^{3}$ rawbiogas in the base, biogas hydrate and biomethane hydrate scenarios, respectively. The climate impact with 1,000 km transport distance was 200.0, 612.0 and $429.0 \mathrm{~g} \mathrm{CO}_{2}$ eq. $/ \mathrm{Nm}^{3}$ rawbiogas in the base, biomethane hydrate and biogas hydrate scenarios, respectively. The amount 
TABLE 6 | Change (\%) in primary energy (PE) input per functional unit when selected input parameters were changed in the three scenarios studied.

\begin{tabular}{|c|c|c|c|c|}
\hline \multirow[t]{2}{*}{ Scenarios } & \multicolumn{2}{|c|}{ Electricity mix } & \multirow{2}{*}{$\begin{array}{l}1,000 \mathrm{~km} \\
\text { transport }\end{array}$} & \multirow{2}{*}{$\begin{array}{c}100 \% \\
\text { Hydration } \\
\text { efficiency }\end{array}$} \\
\hline & Natural gas & Hydropower & & \\
\hline Base (CBG) & +104 & -44 & +215 & - \\
\hline Biogas hydrate & +124 & -40 & +75 & -6 \\
\hline $\begin{array}{l}\text { Biomethane } \\
\text { hydrate }\end{array}$ & +126 & -50 & +43 & -6 \\
\hline
\end{tabular}

of biomethane transported in the different scenarios was within the same range, while the total mass transported per trip was higher in the base scenario than in the hydrate scenarios (Supplementary Table 1).

In the base scenario, the Swedish electricity mix was used for the LCA calculations. In the sensitivity analysis, the results were compared with those for natural gas-based electricity, as a representative of fossil-based electricity, and hydro-based electricity, as a complete fossil-free electricity. The PE factors and climate impact used in the sensitivity analysis for the different electricity mixes are presented in Table 1. Choice of fossil-free electricity considerably decreased the PE input and climate impact in all scenarios. With the fossil-free option, the $\mathrm{PE}$ inputs decreased to $1.6,6.5$ and $4.0 \mathrm{MJ} / \mathrm{Nm}^{3}$ rawbiogas and the climate impact decreased to $126.0,482.0$ and $366.0 \mathrm{~g} \mathrm{CO}_{2}$ eq. $/ \mathrm{Nm}^{3}$ rawbiogas in the base, biogas hydrate and biomethane hydrate scenarios, respectively. Choice of fossil-based electricity significantly increased the PE input and climate impact of the scenarios, especially the gas hydrate scenarios due to the high electricity input in the hydrate formation and dissociation processes.

With the fossil-based electricity mix, the PE inputs increased to $6.0,26.0$ and $18.6 \mathrm{MJ} / \mathrm{Nm}^{3}$ rawbiogas and the climate impact increased to 252.0, 1242.0 and $765.0 \mathrm{~g} \mathrm{CO}_{2}$ eq. $/ \mathrm{Nm}^{3}$ rawbiogas in the base, biogas hydrate and biomethane hydrate scenarios, respectively.

Methane losses from the upgrading stage played an important role in the climate performance of all scenarios. Reducing the $\mathrm{CH}_{4}$ losses to $0.5 \%$ ( $1 \%$ in the original scenario) resulted in a total climate impact of 80.0, 454.0 and $341.0 \mathrm{~g} \mathrm{CO}_{2}$ eq. $/ \mathrm{Nm}^{3}$ rawbiogas in the base, biogas hydrate and biomethane hydrate scenarios, respectively. Increasing the $\mathrm{CH}_{4}$ losses to $2 \%$ resulted in a climate impact of 260.0, 663.0 and $515.0 \mathrm{~g} \mathrm{CO}_{2}$ eq. $/ \mathrm{Nm}^{3}$ rawbiogas in the base, biogas hydrate and biomethane hydrate scenarios, respectively.

Gas handling in the hydrate formation and dissociation units led to gas losses, including losses of $\mathrm{CH}_{4}$, which contributed to the climate impact and reduced the performance of the hydrate scenarios. Reducing the $\mathrm{CH}_{4}$ losses during gas handling from 2 to $0.5 \%$ in the hydrate scenarios resulted in a climate impact of 311.0 and $270.0 \mathrm{~g} \mathrm{CO}_{2}$ eq. $/ \mathrm{Nm}^{3}$ rawbiogas in the biogas hydrate and biomethane hydrate scenarios, respectively. Doubling the $\mathrm{CH}_{4}$ losses to $4 \%$ during gas handling in the hydrate scenarios increased the climate impact to 907.0 and $520.0 \mathrm{~g} \mathrm{CO}_{2}$ eq. $/ \mathrm{Nm}^{3}$ rawbiogas in the biogas hydrate and biomethane hydrate scenarios, respectively.

Based on the assumption of hydrate formation from liquid water, the efficiency of gas contact with water plays a key role in the formation of gas hydrates. Changing the hydration efficiency from $80 \%$ to $100 \%$ based on a hydration number of $1: 5.75$ were tested in the sensitivity analysis. In a modeling study by Anderson (2004), the hydration number was shown to vary with temperature and pressure. Within the temperature range $0-45^{\circ} \mathrm{C}$, the hydration number was calculated to be highest $(6.12)$ at $12^{\circ} \mathrm{C}$ and lowest (5.71) at $20^{\circ} \mathrm{C}$. With the ideal hydration number for a structure I-hydrate (1:5.75) and an efficiency of $80 \%$ used in this study, the hydrate would contain $137.0 \mathrm{~m}^{3} \mathrm{CH}_{4} / \mathrm{m}^{3}$ hydrate (Norberg et al., 2013). Assuming that the ideal hydration number could be obtained with $100 \%$ efficiency, i.e., containing 164 $\mathrm{m}^{3} \mathrm{CH}_{4} / \mathrm{m}^{3}$ (Pellenbarg and Max, 2000), the total PE input would decrease to 10.8 and $7.7 \mathrm{MJ} / \mathrm{Nm}^{3}$ rawbiogas and the climate impact would decrease to 544.0 and $403.0 \mathrm{~g} \mathrm{CO}_{2}$-eq. $/ \mathrm{Nm}^{3}$ rawbiogas for the biogas hydrate and biomethane hydrate scenarios, respectively.

\section{DISCUSSION}

The gas hydrate scenarios examined in this study had a lower energy output/input ratio and a higher climate impact than in the base scenario, where biomethane was assumed to be distributed as CBG. The main processes in the hydrate scenarios associated with high energy use and climate impact were hydrate formation and dissociation. Comparing the hydrate scenarios, the biomethane hydrate scenario showed better energy performance than the biogas hydrate scenario, while the climate impact was approximately similar for both gas hydrate scenarios. This indicates that biogas should preferably be upgraded before

TABLE 7 | Change (\%) in global warming potential per functional unit when selected input parameters were changed in the three scenarios studied.

\begin{tabular}{|c|c|c|c|c|c|c|c|c|}
\hline \multirow[t]{3}{*}{ Scenarios } & \multicolumn{4}{|c|}{ Methane loss } & \multicolumn{2}{|c|}{ Electricity mix } & \multirow[t]{3}{*}{ 1,000 km transport } & \multirow[t]{3}{*}{$100 \%$ Hydration efficiency } \\
\hline & \multicolumn{2}{|c|}{ Upgrading } & \multicolumn{2}{|c|}{$\begin{array}{l}\text { Hydration formation and } \\
\text { disassociation }\end{array}$} & \multirow[t]{2}{*}{ Natural gas } & \multirow[t]{2}{*}{ Hydro-power } & & \\
\hline & $0.5 \%$ & $2.0 \%$ & $0.5 \%$ & $4.0 \%$ & & & & \\
\hline Base (CBG) & -43 & +85 & - & - & +79 & -12 & +42 & - \\
\hline Biogas hydrate & -20 & +17 & -45 & +60 & +90 & -15 & +8 & -4 \\
\hline Biomethane hydrate & -18 & +24 & -35 & +25 & +103 & -12 & +3 & -3 \\
\hline
\end{tabular}


hydration. However, the futuristic approach of the hydrate scenarios means that considerable uncertainties are embedded in the results, since assumptions had to be made due to lack of experiences and data. The lack of a detailed technical description and performance data on the hydrate formation and dissociation processes is clearly a limitation. In the absence of such data, the energy calculations were based on thermodynamic considerations and assumptions on conversion efficiencies. Furthermore, the $\mathrm{CH}_{4}$ losses related to hydrate formation and dissociation had to be assumed and were taken to be in the same range as for biogas upgrading.

The results from the sensitivity analysis indicated that changing to hydropower electricity, increasing the transport distance, reducing $\mathrm{CH}_{4}$ losses from both upgrading and hydrate handling and increasing the hydration efficiency to an ideal hydration number would not make the hydrate scenarios competitive in comparison with conventional CBG storage and distribution. However, when the transport distance was increased to $1,000 \mathrm{~km}$, the $\mathrm{PE}$ inputs and climate impact in the hydrate scenarios were less affected than those in the base scenario, since the conventional CBG transport included heavier total mass transport due to the steel tanks used for compressed biomethane.

Methane losses made an important contribution to the climate impact ( $45 \%$ and $35 \%$ for the biogas hydrate and biomethane hydrate scenarios, respectively). Choice of electricity mix is a notoriously influential factor for the outcome of LCA studies. Changing from the Swedish electricity mix to hydropower in the present case reduced the PE inputs of all scenarios by $\sim 50 \%$, while using natural gas-based electricity more than doubled the PE input.

The results obtained in this study indicate that using hydrate as a means of transporting gas from a production site for use at another site is not favorable in terms of energy use. In future studies, it would be interesting to study integration of hydrates for storage at centralized biogas plants.

In the present study, cooling for hydrate formation and heating for hydrate dissociation dissociationwas assumed to be performed by a compression chiller and heat pump, respectively. This resulted in high electricity consumption, which understandably resulted in an increase in both the PE input and the climate impact. Therefore, integration with e.g., return water in a district heating system or using surplus heat from a combined heat and power plant for dissociation heat could help to improve the energy balance. Moreover, expansion of the system to include the anaerobic digestion process, where low-grade heat from cooling during hydrate formation could be used, would likely improve the overall efficiency of an integrated system. In addition to system integration, it is also important to consider future developments in hydrate technologies. In $\mathrm{CH}_{4}-\mathrm{CO}_{2}$ hydrate mixtures, the $\mathrm{CO}_{2}$ is more easily released than the $\mathrm{CH}_{4}$ (Kwon et al., 2011), a difference that could be exploited in an upgrading process (Arca et al., 2011; Silva, 2016). This would make it possible to integrate dissociation and upgrading in one process (Sun et al., 2015; Castellani et al., 2018). Furthermore, the use of detergents such as sodium dodecyl sulfate has been shown to enhance the hydrate formation rate at lower pressures with reduced stirring, resulting in lower energy input (Zhong and Rogers, 2000). Thus, system integration and technical developments could reduce the limitations of hydrate use on an industrial scale.

Within the present study boundaries, material consumption and capital investments were not considered, but they are high in all scenarios. For instance, in the base scenario, highpressure capsules for compressed biomethane (CBG) storage and transport are made from steel, steel alloys or aluminum, along with other metallic elements. Gas hydrates are confined in a water medium, which does not require very high pressure or low temperatures.

European Department of Transportation regulations classify $\mathrm{CBG}$ as a flammable and hazardous material. Major requirements for road transportation include approved tanks (e.g., seamless steel cylinders), specific tank pressure and vapor content (i.e., less than $10 \mathrm{ppm} \mathrm{H}_{2} \mathrm{O}$ ) and a minimum methane content of $97 \%$. Additional compression at the biomethane filling point is also required, which leads to gas loss and GHG emissions. Transport of biomethane as CBG is not a solution for very long distances due to technical requirement and investment cost. As previously mentioned LBG is an energy intensive technology restricted to large-scale biomethane production units.

Gas hydrate technology could be considered an alternative to $\mathrm{CBG}$ and $\mathrm{LBG}$ systems, as it could be distributed in medium quantities over an average distance and would be very efficient for large-scale biomethane storage units due to high withdrawal flow rate (Mimachi et al., 2015; Budzianowski and Brodacka, 2017). During storage, $\mathrm{CH}_{4}$ emissions occur when the temperature is over $4^{\circ} \mathrm{C}$ and the storage pressure is lower than atmospheric pressure, which is of interest under the prevailing climate conditions in Sweden. Thus, there is promising scope for technical developments that could reduce the limitations of future hydrate use in industrial scale (Moghaddam, 2019).

A life cycle perspective was applied in this study, covering the energy inputs and GHG emissions from using biogas and biomethane hydrates for storage and transport in comparison with CBG. Production of raw material, anaerobic digestion and the filling unit were identical in all scenarios and were omitted from the analysis. Performing a complete LCA study could delay use of results in decision making and product development due to complexity, slowness and lack of detailed data in the initial stages. Identification of different parts of a services or product system that could be neglected during the analysis, without significantly affecting the overall results, leads to a reduced amount of data (Pelton and Smith, 2015). The results obtained could be combined with an extended economic inputoutput (EEIO) study to identify key hotspot inputs and stages within the biomethane life cycle and compare the environmental benefits against a baseline scenario. Implementing hotspot system analysis (HSA) would add a further dimension, particularly as regards sustainability purchasing criteria.

\section{CONCLUSION}

The current study aimed to investigate gas hydrates as an alternative technology for biogas road distribution 
which is one of the current barriers to the wider implementation of biogas as a source of renewable energy as the temporary supply problems have affected the trust for the vehicle biogas market in Sweden.

The study concludes that the hydration conversion process and dehydration require a high electricity input and contribute to high levels of GHG emissions. Even with suggested improvements to the biomethane hydrate production process, such as minimizing $\mathrm{CH}_{4}$ losses from hydrate formation and dissociation and from gas upgrading to biomethane, the total energy requirement was $227.0 \mathrm{~g} \mathrm{CO}_{2}$ eq. $/ \mathrm{Nm}^{3}$ rawbiogas, which was almost twice the climate impact in the base (CBG) scenario.

To reduce the limitations for future use of hydrate as a mean for biogas and biomethane distribution, it is important to consider aspects on system integration and technical development. A combination of technological development (e.g., hydration efficiency and gas upgrading) and use of a completely clean source of electricity (e.g., 100\% hydropower electricity mix) would significantly increase the potential for biomethane storage and distribution via gas hydrates.

\section{REFERENCES}

Anderson, G. K. (2004). Enthalpy of dissociation and hydration number of methane hydrate from the Clapeyron equation. J. Chem. Thermodyn. 36, 1119-1127. doi: 10.1016/j.jct.2004.07.005

Arca, S., Poletti, L., Poletti, R., and D’Alessandro, E. (2011). "Upgrading of biogas technology through the application of gas hydrates," in the Proceedings of the 7th International Conference on Gas Hydrates (ICGH 2011), Edinburgh, Scotland, United Kingdom (Red Hook, NY: Curran Associates, Inc).

Bauer, F., Hulteberg, C., Persson, T., and Tamm, D. (2013). Biogas UpgradingReview of Commercial Technologies, SGC Rapport. Malmö: Swedish Gas Technology Center.

Benjaminsson, J., and Nilsson, R. (2009). Forms of Distribution for Biogas and Natural Gas in Sweden (Distributionsformer för Biogas Och Naturgas I Sverige). Stockholm: Grontmij.

Budzianowski, W. M., and Brodacka, M. (2017). Biomethane storage: evaluation of technologies, end uses, business models, and sustainability. Energy Convers. Manag. 141, 254-273. doi: 10.1016/j.enconman.2016.08.071

Byman, K. (2016). Electricity Production in Sweden Iva's Electricity Crossroads Project. Stockholm: Royal Swedish Academy of Engineering Sciences.

Castellani, B., Rinaldi, S., Bonamente, E., Nicolini, A., Rossi, F., and Cotana, F. (2018). Carbon and energy footprint of the hydrate-based biogas upgrading process integrated with CO2 valorization. Sci. Total Environ. 615, 404-411. doi: 10.1016/j.scitotenv.2017.09.254

Cherubini, F., and Strømman, A. H. (2011). Life cycle assessment of bioenergy systems: state of the art and future challenges. Bioresour. Technol. 102, 437-451. doi: 10.1016/j.biortech.2010.08.010

Curran, M. A. (2015). Life Cycle Assessment Student Handbook. Hoboken, NJ: John Wiley and Sons.

Ecoinvent (2017). Ecoinvent 3.3 Swiss Centre for Life Cycle Inventories. Zurich.

Ershov, E. D., and Yakushev, V. S. (1992). Experimental research on gas hydrate decomposition in frozen rocks. Cold Reg. Sci. Technol. 20, 147-156. doi: 10. 1016/0165-232x(92)90014-1

European Union Directive. (2009). 2009/28/EC of the European Parliament and of the Council of 23 April 2009 on the Promotion of the Use of Energy from Renewable Sources and Amending and Subsequently Repealing Directives 2001/77/EC and 2003/30/EC. COD (2008) 0016. Brussels: European Union Directive.

Geerolf, L. (2018). The Biogas Sector Development: Current and Future Trends in Western and Northern Europe. Stockholm: KTH School of Industrial Engineering and Management Energy Technology.

\section{DATA AVAILABILITY STATEMENT}

The original contributions presented in the study are included in the article/Supplementary Material, further inquiries can be directed to the corresponding author/s.

\section{AUTHOR CONTRIBUTIONS}

ÅN supervised the work. EM collected the data, carried out the LCA study, and wrote the manuscript. AL and ÅN conceptualized the work, PT, AL, and ÅN contributed to data inventory and reviewing and editing the article. All authors contributed to the article and approved the submitted version.

\section{SUPPLEMENTARY MATERIAL}

The Supplementary Material for this article can be found online at: https://www.frontiersin.org/articles/10.3389/fenrg. 2021.568879/full\#supplementary-material

Grant, T., and Bengtsson, J. (2017). Report for the Australian Renewable Energy Agency Method and Guidance for Undertaking Life Cycle Assessment (LCA) of Bioenergy Products and Projects. Canberra, NSW: Australian Renewable Energy Agency.

Gudmundsson, J. S. (1996). Method for Production of Gas Hydrates for Transportation and Storage. U.S. Patent No. 5,536,893. Washington, DC: U.S. Patent and Trademark Office.

Gudmundsson, J. S., Graff, O. F., Hove, A. M., and Laading, G. (1999). Natural Gas Hydrate (NGH) Technology for Stranded Gas. London: IBC Remote Gas Utilization.

Gudmundsson, J. S., Parlaktuna, M., and Khokhar, A. A. (1994). Storing of natural gas as frozen hydrate. Soc. Pet. Eng. 9, 69-73. doi: 10.2118/24924-pa

Hjort, A., and Tamm, D. (2012). Transport Alternatives for Biogas in the Region of Skane. Intelligent Energy Europe Programme. Skane: BioMil AB.

IPCC (2006). IPCC Guidelines for National Greenhouse Gas Inventories, Prepared by the National Greenhouse Gas Inventories Programme. Japan: IGES.

ISO. (2006a). Environmental Management-Life Cycle Assessment-Principles and Framework (ISO 14040:2006). Brussels: European Committee for Standardization.

ISO. (2006b). Environmental Management_Life Cycle Assessment-Requirements and Guidelines (ISO 14044:2006). Brussels: European Committee for Standardization.

Kang, S. P., Seo, Y., and Yang, W. (2009). Kinetics of methane and carbon dioxide hydrate formation in silica gel pores. Energy Fuels 23, 3711-3715. doi: 10.1021/ ef900256f

Kwon, T. H., Kneafsey, T. J., and Rees, E. V. L. (2011). Thermal dissociation behavior and dissociation enthalpies of methane-carbon dioxide mixed hydrates. J. Phys. Chem. B 115, 8169-8175. doi: 10.1021/jp111490w

Lantz, M., Ekman, A., and Börjesson, P. (2009). System-Optimized Production of Vehicle Gas - an Environmental and Energy System Analysis of Söderåsen's Biogas Plant (Systemoptimerad Produktion Av Fordonsgas - En Miljö- Och Energisystemanalys Av Söderåsens Biogasanläggning). Lund: Lund University Department of Technology and Society.

Mimachi, H., Takahashi, M., Takeya, S., Gotoh, Y., Yoneyama, A., Hyodo, K., et al. (2015). Effect of long-term storage and thermal history on the gas content of natural gas hydrate pellets under ambient pressure. Energy Fuels 29, 4827-4834. doi: 10.1021/acs.energyfuels.5b00832

Moghaddam, E. A. (2019). Life Cycle Assessment of Novel Biomethane Systems. Doctoral thesis, Swedish University of Agricultural Sciences, Uppsala, Sweden.

Moghaddam, E. A., Ahlgren, S., Hulteberg, C., and Nordberg, А̊ (2015). Energy balance and global warming potential of biogas-based fuels from a life cycle 
perspective. Fuel Process. Technol. 132, 74-82. doi: 10.1016/j.fuproc.2014.12. 014

Mori, Y. H. (2003). Recent advances in hydrate-based technologies for natural gas storage-a review. J. Chem. Ind. Eng. 54, 1-17.

Norberg, I., Nordberg, A, Larsolle, A., and Andersson, J. (2013). Hydrate for Transport and Storage of Biogas and Biomethane: a Scenario Study. Report No 2013:18, f3. Uppsala: The Swedish Knowledge Centre for Renewable Transportation Fuels.

Pang, W. X., Xu, W. Y., Sun, C. Y., Zhang, C. L., and Chen, G. J. (2009). Methane hydrate dissociation experiment in a middle-sized quiescent reactor using thermal method. Fuel 88, 497-503. doi: 10.1016/j.fuel.2008.11.002

Pellenbarg, R. E., and Max, M. D. (2000). "Introduction, physical properties and natural occurrences of hydrate," in Natural Gas Hydrate in Oceanic and Permafrost Environments, ed. M. D. Max (Dordrecht: Kluwer Academic), 1-8. doi: 10.1007/978-94-011-4387-5_1

Pelton, R. E., and Smith, T. M. (2015). Hotspot scenario analysis: comparative streamlined LCA approaches for green supply chain and procurement decision making. J. Ind. Ecol. 19, 427-440. doi: 10.1111/jiec.12191

Siažik, J., Malcho, M., and Čaja, A. (2017). "Calculation of the eroei coefficient for natural gas hydrates in laboratory conditions," in Proceedings of the AIP Conference Proceedings (Melville, NY: AIP Publishing).

Silva, L. P. S. (2016). Gas Separation by Gas Hydrate Selective Crystallization for the Valorization of Biogas. Doctoral dissertation, Universite Paris-Saclay, Saint-Aubin, France.

Sloan, E. D. Jr., and Koh, C. (2007). Clathrate Hydrates of Natural Gases. Boca Raton, FL: CRC press.

Stocker, T. F., Qin, D., Plattner, G. K., Alexander, L. V., Allen, S. K., Bindoff, N., et al. (2013). "Technical summary," in Climate Change 2013: the Physical Science Basis. Contribution of Working Group $i$ to the Fifth Assessment Report of the Intergovernmental Panel on Climate Change 33-11, eds T. F. Stocker, D. Qin, G. K. Plattner, and M. Tignor (Cambridge: Cambridge University Press).

Sun, Q., Li, H., Yan, J., Liu, L., Yu, Z., and Yu, X. (2015). Selection of appropriate biogas upgrading technology-a review of biogas cleaning, upgrading and utilisation. Renew. Sustain. Energy Rev. 51, 521-532. doi: 10.1016/j.rser.2015. 06.029

Sun, R., Fan, Z., Yang, M., Pang, W., Li, Y., and Song, Y. (2019). Experimental investigation into the dissociation of methane hydrate near ice-freezing point induced by depressurization and the concomitant metastable phases. J. Nat. Gas Sci. Eng. 65, 125-134. doi: 10.1016/j.jngse.2019.03.001

Swedish Energy Agency. (2018). Production and Use of Biogas and Digestate in 2018 (Produktion Och Användning Av Biogas Och Rötrester År 2018). Available online at: https://www.energigas.se/library/2622/produktion-ochanvaendning-av-biogas-och-roetrester-aar-2018.pdf (accessed February 10, 2020).

Uchida, T., Ikeda, I. Y., Takeya, S., Kamata, Y., Ohmura, R., Nagao, J., et al. (2005). Kinetics and stability of $\mathrm{CH} 4-\mathrm{CO} 2$ mixed gas hydrates during formation and long-term storage. ChemPhysChem 6, 646-654. doi: 10.1002/cphc.2004 00364

Wang, P., Wang, S., Song, Y., and Yang, M. (2017). Methane hydrate formation and decomposition properties during gas migration in porous medium. Energy Procedia 105, 4668-4673. doi: 10.1016/j.egypro.2017.03.1012

Wellinger, A., Murphy, J. D., and Baxter, D. (2013). The Biogas Handbook: Science, Production and Applications. Amsterdam: Elsevier.

Wu, Q., Yu, Y., Zhang, B., Gao, X., and Zhang, Q. (2019). Effect of temperature on safety and stability of gas hydrate during coal mine gas storage and transportation. Saf. Sci. 118, 264-272. doi: 10.1016/j.ssci.2019.04. 034

Zamagni, A., Guinée, J., Heijungs, R., Masoni, P., and Raggi, A. (2012). Lights and shadows in consequential LCA. Int. J. Life Cycle Assess. 17, 904-918. doi: 10.1007/s11367-012-0423-x

Zhong, Y., and Rogers, R. E. (2000). Surfactant effects on gas hydrate formation. Chem. Eng. Sci. 55, 4175-4187. doi: 10.1016/s0009-2509(00)00072-5

Conflict of Interest: The authors declare that the research was conducted in the absence of any commercial or financial relationships that could be construed as a potential conflict of interest.

Copyright (c) 2021 Moghaddam, Larsolle, Tidåker and Nordberg. This is an openaccess article distributed under the terms of the Creative Commons Attribution License (CC BY). The use, distribution or reproduction in other forums is permitted, provided the original author(s) and the copyright owner(s) are credited and that the original publication in this journal is cited, in accordance with accepted academic practice. No use, distribution or reproduction is permitted which does not comply with these terms. 